\title{
Linguistic Learning: A New Conceptual Focus in Knowledge Visualization
}

\author{
Stefan Bertschi \\ University of St. Gallen \\ stefan.bertschi@unisg.ch
}

\author{
Noah Bubenhofer \\ University of Zurich \\ noah.bubenhofer@access.unizh.ch
}

\begin{abstract}
In this paper we examine the metaphorical face of knowledge visualization and weave our observations into a wider perspective. We discuss a fundamental, but less scrutinized, precondition: the interrelation of metaphor, 'linguistic learning' and mediation of knowledge through visualization. By presenting preliminary thoughts on this interrelation, we wish to avoid the risk of simplification within this new field of research and to provide a potential theoretical foundation.
\end{abstract}

\section{Linguistic preliminaries}

...as reported yesterday - is survived by - let us propose a toast - for immediate release - passed into eternity - we showed that - with kind regards...

These phrases have a familiar ring. Still we have trouble to accept them as meaningful in the shown combination. Yet individually they remind us of specific text types (or genres, 'Textsorten') or communicative settings. These examples represent more or less fixed multi-word units, so-called phraseologisms. They emanate, for example, from the following text types:

- $\quad$ press report ('as reported yesterday'),

- $\quad$ press release ('for immediate release'),

- $\quad$ address ('let us propose a toast'),

- obituary ('is survived by' or 'passed into eternity'),

- $\quad$ scientific paper ('we showed that') and

- $\quad$ private letter ('with kind regards').

\subsection{Patterns and communication}

According to linguist Helmuth Feilke, such patterns (or exemplariness, 'Musterhaftigkeit') come into existence by means of communication. The social behavior of speakers, their common sense competence, leads to normative structures in language [1, p. 8]. It concerns "preferences for the understanding and the production of phrases" [1, p. 19, our translation]. These preferences emerge through a process of selectivity generated in communication. Feilke termed this mechanism of linguistic structuring idiomatic coinage ('idiomatische Prägung'). The words people use in everyday communication become semantically coined: "The principle of idiomatic coinage is based on the fact that expression units ('Ausdruckseinheiten'), which can be combined relatively freely because of their paradigmatic qualities, are coined on the syntagmatic axis and, therefore, become figure-like ('gestalthafte') expression units." [1, p. 17, our translation]

Feilke recognizes this basic principle on different levels of language structure: on the level of phonemes (phonotactic clusters), morphemes (usual compounds or derivatives), syntactic phrases (lexical collocations, idioms, phraseologisms etc), sentences and phrases (abstract sentence patterns, routine formulae) and finally on the level of whole texts (textual patterns) [1]. We shall not elaborate in further detail on the principle of common sense competence, but instead refer to [2] and [3].

\subsection{Patterns and culture}

If the exemplariness of a language is constituted by its speakers' social behavior, it suddenly reflects social structures (a culture). This would imply that, in return, the exemplariness of a language can be analyzed to reveal and describe this specific culture. Some approaches of cultural and discourse analysis try to avail themselves of this interrelation $[4,5]$. Still, exemplariness of language is rarely analyzed to the necessary extent, and there are other approaches evolving. For example, one that proposes determining basic semantic figures in discourse ('diskurssemantische Grundfiguren') by analyzing semantic fields or feature oppositions [6]. 
Nevertheless, it can be demonstrated how exemplariness can be fruitfully used in cultural analysis. In a historical context, "linguistic forms, [...] routines and patterns of language use" are considered in order to analyze the "production and dynamic sampling of sociocultural processes" [7, p. 46, our translation]. The cultural conditionality of language not only helps the observer to describe culture and transculturation, but in the first instance, it helps a society to constitute itself and its perception (or even its cognition which is a synonym for knowledge). Hence, this social knowledge is relevant in two ways: First, from an observer's perspective, it is the observer's intention to become acquainted with the society's knowledge. But in doing so, knowledge is concurrently reconstructed through the process of observation. Second, from the perspective of the observed, knowledge is a subject of communication and is constantly being reconstructed through communication.

Therefore, this reconstruction is carried out by language use and - this is the clou - by applying the exemplariness of language. By using linguistic patterns one does not have to verbalize knowledge assets every time anew and in person, but can tap these assets through already existing patterns, and refer to them with a few signs. (This once again reveals the neglected connection between language and culture, and between phraseologisms and the cultural prerequisites for understanding and using them.)

\section{Knowledge Visualization: prima vista}

Techniques that are subsumed under the term knowledge visualization aim particularly at portraying the reconstruction of patterns:

"Knowledge visualization [...] facilitates the transfer and creation of knowledge among people by giving them richer means of expressing what they know. [...] $[\mathrm{K}]$ nowledge visualization primarily is used to augment knowledge-intensive communication among individuals. [...] Knowledge visualization can help to solve several predominant, knowledge-related problems in organizations. [...] Knowledge visualization designates all graphic means that can be used to develop or convey insights, experiences, methods, or skills." [10]

Prima vista, it seems as if knowledge visualization is more concerned with pictures than with words. But Eppler and Burkhard propose a whole framework of practices to mediate knowledge through visualization [10]. Among them is the so-called visual metaphor (see section 3.3).

Knowledge visualization aims to graphically 'illustrate' a common cultural process, i.e. to use the exemplariness of language to negotiate knowledge. If such an illustration is depicted graphically, it is at best rele- vant as a means of learning psychology. More relevant is the question of whether new illustrations, which are not integrated into a society's knowledge, are possible at all, and, if they are possible, do they make sense? This is questionable because an illustration can only be processed efficiently if it follows basic semantic figures in discourse and if it is compatible with existing linguistic patterns.

\section{Knowledge Visualization: secunda vista}

Visualization often means representing what is not visible beforehand: "To convert tacit knowledge into explicit knowledge means finding a way to express the inexpressible." [17] If a benefit is to be obtained, every visualization has to be an idealization of reality and, therefore, runs the risk of oversimplification and falsification [10]. In the following, we take a 'secunda vista' at knowledge visualization by analyzing the use of metaphors and visual metaphors in particular.

\subsection{Metaphors}

In the majority of cases, it is not possible to communicate in pictures alone. For this purpose, pictures are too complex, even if (or possibly because) they seem to be worth a thousand words. In alleging to transfer knowledge more effectively they seriously belie their complexity. Communication always calls for language, be it imaginary or articulated. In most cases, pictures need a caption. In addition, there is the impossibility of non-metaphorical thought because metaphoricity of language is total $[8,29]$. Linguistic visualization is the application of metaphors in the broadest sense. Regarding its metaphoricity, we contend that pictorial and linguistic visualization is one and the same. These two visualizations are two sides of the same coin: They are complementary parts of communication.

We mentioned the significance of linguistic patterns for successful communication, and, at the same time, we referred to the social conditionality of these patterns. In order that a visualization is notably impressive and effective, it may be necessary to choose a rather unusual one for a specific context, but it most definitely needs to have a high profile or high name recognition. Every visualization is a frequently used linguistic pattern or is, at least, based upon one. Visualization, for example, works with an unobtrusive 'pie chart' or a more complex 'tube map' which can be exhausted of its metaphoricity $[15,30]$. Because users of such visualizations lay claim to common linguistic patterns, they directly tap the connecting section of a social or cultural discourse. While there is obviously a benefit to be gained from such visualizations, as is ac- 
centuated by Eppler and Burkhard [10], there are still unmentioned risks as well. The potential perceptions and interpretations are severely restrained.

To illustrate this, let us think of 'market shares' visualized by a pie chart. It is common to speak about 'pieces' (of a pie) which are 'cut off' or which are 'distributed among each other', which are 'evenly spread' or 'redistributed', which are '(too) small' or '(too) big'. This imagery biases our perception of 'market' (which is obviously also a metaphor).

Let us tentatively explore an alternative (threedimensional) imagery. This uses a 'starry sky' to visualize the penetration of a community of consumers with goods from specific manufacturers. Each star represents a product. In an infinite space there are brighter and darker stars, emerging and waning stars. The distances between the stars vary depending on the observer's position. The stars' situation in relation to each other depends on gravitation. It should be palpable that this imagery evokes another impression or reality of 'market shares'. The metaphor of a 'tube map' restrains the potential perceptions (of project organization) too. Alternative metaphors are possible and can suddenly evoke different impressions of the matter.

The picture we are using to illustrate a specific circumstance is defined by the language use in a specific culture at a specific time. It is questionable whether it would be possible to use the metaphor of the 'starry sky' to visualize market shares in an annual report. This is mainly because such a practice would infringe an unspoken rule of visualization patterns in a specific context.

The picture is suddenly stabilized not only because it is context-dependent but also because "[m]etaphors may create realities for us, especially social realities." [8] By doing so it can be expected that they produce their own context, and therefore, get into a more or less stable shape [29]. But before they become stabilized through language use, they have one remarkable attribute: Metaphors get attention [15] because they are a driving force in representing novel concepts: "Metaphor is a tool of conceptual economy, but that does not exhaust its role. It is also a tool of discovery, providing a way of imposing or discovering structure within novel or unfamiliar situations." [29] Structure is, at the same time, both an advantage and a disadvantage of metaphors, and of visualized metaphors in particular.

\subsection{Social construction of reality}

Pictures are said to be efficient because humans think in pictures [14, p. 7]. With this proposition the whole foundation that defines the way an individual thinks in pictures is factored out. The remarks on cultural dependencies already illustrated this. The signifi- cation or meaning of pictures (including those of a linguistic-metaphorical nature) depends decisively on the viewer. It is up to him or her "to re-construct meaning." [10] In other words: "[K]nowledge must be recreated in the mind of the receiver" [10]. The recipient has (to be able) to retranslate the visuals used into his or her own language.

A suitable model for such 're-translation' can possibly be detected in a sociolinguistic theory of learning (as shown below). Generally, the most ostensible question would be: What is knowledge as seen by the sociology of knowledge or from a constructivist perspective? "The principal thesis of the sociology of knowledge is that there are modes of thought which cannot be adequately understood as long as their social origins are obscured." [26, p. 2] Even though thinking is closely connected to individuals, greater scope is necessary to understand its true meaning. Therefore, the more recent sociology of knowledge concentrates on this meaning: "And insofar as all human 'knowledge' is developed, transmitted and maintained in social situations, the sociology of knowledge must seek to understand the processes by which this is done in such a way that a taken-for-granted 'reality' congeals for the man in the street. In other words, we contend that the sociology of knowledge is concerned with the analysis of the social construction of reality." [11, p. 3] Sociology of knowledge deals with pattern recognition (asking how we are able to 'see' the world through the eyes of other people and to understand the subjective meaning of their experiences). Together with the former contention this leads back to the phraseologisms and metaphors mentioned earlier. For the recipient to be able to recognize and assign certain patterns or contents, he or she must acquire (or better: learn) certain skills.

Pattern recognition is connected to the notion that "a certain knowledge [...] is not only informative, entertaining or opinion-making but in principle it can have an infinite number of functions" [12, p. 31, our translation]. The process of mediation comes to the fore (including arrangements and attributes of recipients, situation, length and form of presentation etc). In economic settings this is usually done overhastily (because, after Drucker [27], there is still a mystification of knowledge in place within the knowledge economy) whereupon crucial details are ignored. For example, the medium of knowledge visualization is in most cases a metaphor: "Visual metaphors combine the creative leap of sketches with the analytic rationality of conceptual diagrams and employ graphic metaphors to structure information and convey normative knowledge through the connotations of the employed metaphor." $[14$, p. 10] Following this description, the contextual subject and theme, the social and cultural relevance are 
quickly ignored. This is problematic because exactly these details are included in a metaphor. Moreover, these manifold dependencies suggest that continuously planned and generated mediation can hardly exist [13]. At least it cannot be explicit and effective to the full extent.

\subsection{Visual metaphors}

As stated earlier, visual metaphors are an important means of knowledge visualization: "Visual metaphors used for knowledge transfer or creation can either be natural objects or phenomena (e.g. mountains, icebergs, tornados) or artificial, man-made objects (e.g. a bridge, a ladder, a temple), activities (e.g. climbing, etc), or concepts (e.g. war, family). Their main feature is that they organize information meaningfully. In doing so, they fulfill a dual function: first, they position information graphically to organize and structure it. Second, they convey an implicit insight [into] the information represented through the key characteristics (or associations) of the metaphor that is employed." [10, our italics] But even visual metaphors cannot ensure that meaning is transferred identically to all recipients.

This is rather severe because not only the 'visualization format' or 'visualization type perspective', specifically labelled as visual metaphors, uses metaphors as a primary instrument $[18,25]$. 'Heuristic sketches', 'conceptual diagrams', 'knowledge animations' as well as 'knowledge maps' use metaphors more or less to confer expression and to optimize knowledge transfer. This can certainly be stated for diagrams and maps [30]. Metaphoricity can be seen best by considering the 'tube map visualization' as an example. This format "is a powerful metaphor" per se [as stated in 14, p. 19, see 15]. If additionally 'storytelling' [16] is taken into account as a 'visualization type perspective', as in [25], the 'visual language' in its purest form is achieved. Solely through language, pictures automatically come into existence in the reader's head - but with the constraint that these pictures are not necessarily identical in different recipient's heads.

The advantages of common 'visual metaphors', their dual function is seen in [10], have already been quoted earlier. From a practical point of view it can be added that "the viewer can relate what is new (the expert's insights) to what he or she already understands (the metaphor's main characteristic)." [30, p. 81] Visual metaphors offer powerful templates to communicate with non-experts. Apart from their ability "to organize information and to give it additional meaning" [30, p. 82], visual metaphors can "facilitate the process of learning." [10] Because of their visibility and metaphoricity they get more attention than other formats, therefore, they facilitate remembering and provide cognitive focus [15].

In our brief analysis of metaphors, we criticized a specific aspect and showed that this specific visualization method, using metaphorical tools like 'pie charts' or 'maps', is severely restricting. Eppler mentions "the risks inherent in using such forms of visualization" but specifies only "the difficult maintenance of the diagrams and maps, the reification of (at times) invalid views, and hence the possible manipulation of users, or the possible distortion of reality through misinterpretation." [30, p. 87] The risks mentioned are limited to those initiated by sender or receiver. The potential risks of using metaphors do not appear. This is, besides the fact that reflected basic principles are still rudimentary in knowledge visualization, our main point of criticism.

Because critical reasoning is widely lacking, knowledge visualization acts on the assumption that the framework and its effectiveness are hardly vulnerable. This may relate to the fact that the discipline of (business-oriented) knowledge visualization is still young [18] and attempts to define it have only been made for a short time $[10,14]$. The mentioned mediation can only come into existence and be effective under commensurate conditions. We assume that the outline of such conditions can be based on principles of 'linguistic learning'.

\section{A constructivist concept of learning}

The fundamental idea of all learning lies in processing information and converting/translating it into evident knowledge. Or speaking with Wittgenstein: "Knowledge is often in the eye of the beholder, and you give meaning to the concept through the way you use it" [19]. Knowledge is not something that is available constantly and at an arbitrary rate. Similar to metaphors it needs to be actively developed and kept alive by intense cooperation with other people.

Watzlawick et al. [20, p. 260] distinguish between two (actually three) levels of knowledge: "knowledge of things and knowledge about things" (partly comparable to 'knowing how' and 'knowing that' in Ryle's [28] terminology). First-order knowledge refers to the awareness of objects that our senses convey. On this level the subject does not know anything about the sensed object yet. The next level contains the knowledge about things (or second-order knowledge). This metaknowledge makes it possible to reveal meaning, build associations, achieve improvements. The sheer knowledge that an artefact (or thought) simply exists (first-order) does not include the ability to handle it. Such an ability is based on the knowledge of how to approach it and how to handle information properly (second-order). This reflection, as third-order know- 
ledge, needs to be improved and used consequently. To sum up in one sentence: I understand why it is important that I am able to assimilate and use this artefact (or thought).

As an important 'building block' in a complex world, third-order knowledge [20, p. 261], comprehension or conclusion about meaning, can assure a hint of certainty. This could be expressed in the following way: It is like it is, because I understand how it is and why it is that way. This three-stage process even allows more. As exemplified by language acquisition, it "makes the acquisition itself progressively easier." [20, p. 262] This involves continued activity that needs to find continuous connection, i.e. needs to be kept alive. Only knowledge (about artefacts/thoughts and their meaning) allows us to explain, reason and adopt specific phenomena. This, likewise, needs to be a precondition for knowledge visualization. Hence, the sender of a message has no possibility to verify whether the recipient has fully understood the imparted knowledge in the way the sender intended [20].

\subsection{External construction}

The underlying notion (that again leads back to the starting point of this paper) was established by Vygotsky, a Russian developmental psychologist in the early 1930s: According to him, higher mental processes are by definition culturally mediated, and are "a function of socially meaningful activity" [23, p. 113]. Because they are functions of mediated activity, the learning process connects the sociocultural sphere to a proximately internalized thought or mind-set (outsideinside). What Vygotsky defines as learning is based on the assumption that higher mental functions are always socially or culturally mediated and context-specific. These functions develop through social interaction, they are social processes.

The source of mediation can be of different kinds: an artefact, a system of symbols, or the behavior of other people. It is, on all occasions, a sociocultural mediation. But, according to Vygotsky, language (i.e. signs and symbols) mediates thought most. He asserted that thought development has to be determined by language: "The relation of thought to word is not a thing but a process, a continual movement back and forth from thought to word and from word to thought. In that process the relation of thought to word undergoes changes which [in] themselves may be regarded as development in the functional sense. Thought is not merely expressed in words; it comes into existence through them. Every thought tends to connect something with something else, to establish a relationship between things. Every thought moves, grows and develops, fulfills a function, solves a problem." [21, p.
218, our italics] This is one possible way that such functions are constituted externally.

The following step, the way by which higher mental functions become individual, is called 'internalization'. Internalization is the "internal reconstruction of an external operation" by which social activities become mental activities. Thus "[a]n operation that initially represents an external activity is reconstructed and begins to occur internally." [22, p. 56] During this operation, "an interpersonal process is transformed into an intrapersonal one" [22, p. 57]. As defined by Vygotsky, it does not merely copy object reality into the mind, "concepts are not absorbed ready-made" [21, p. 161]. Instead, internalization involves people actively processing these object realities or concepts. Following this description, mental functioning is actively constructed by the individual and is the result of social experience. In such an understanding, learning is solely a constructivist activity. Finally, the most interesting aspect is that Vygotsky believed that thought and language could definitely not exist without each other.

\subsection{Internal construction}

A different approach has been proposed by Stahl. On first glance his model seems similar because it "is an attempt to understand learning as a social process incorporating multiple distinguishable phases that constitute a cycle of personal and social knowledgebuilding." [24, p. 70] But contrary to Vygotsky he starts from the internal mind-set or personal unterstanding and moves on to social knowledge-building.

The transition between the internal and the external is depicted by "how personal beliefs that we become aware of in our activity in the world can be articulated in language and enter into a mysterious social process of interaction with other people and with our shared culture." [24, p. 71] It is understood that this is not a one-way process because "culture, in turn, enters into our personal understanding". Because of Stahl's interest in collaborative knowledge-building, his main route is in opposition to Vygotsky's (i.e. inside-outside). Nevertheless, people's "network of 'personal' meanings ultimately has its origin in interpersonal language and culture." [24, p. 72, see 19] Because it is not possible to process all (especially problematic) aspects of personal understanding internally, people enter social settings and create new meanings collaboratively. This is done via language and through public statements. At this point a certain transfer takes place using the route mentioned above. If the following negotiation leads to an "acceptance of a common result, then such a result is accepted as knowledge." [24, p. 72] Similar to Vygotsky, Stahl asserts that knowledge is a socially mediated product. But this time it happens in such a way 
that "beliefs become knowledge through social interaction" [24, p. 72]. Stahl's approach regarding collaborative knowledge-building centers around "the fact that the group has the power to evolve the knowledge further" [24, p. 76].

\subsection{Visual construction}

Both approaches are constructivist in nature. Constructivist theories of learning emphasize meaningmaking through people's active participation in social and cultural contexts and settings. Similar approaches can be found in visual perception theory. Therefore, it is notable that Burkhard devotes a mere three lines to such an approach: "Constructive [visual] perception [...] believes that an individual's perception is based on the combination of sensory information with prior knowledge and previous experience." [25] We prefer this approach to one that privileges direct perception, meaning "that all the information we need to perceive is in the sensory input we receive." [25]

This is the moment when metaphors, connotations and phraseologisms come back into mind. They are irrevocably connected to our innate ability to process visual representations. Metaphors are an excellent method of expressing such notions. They are coined with recognisable patterns and, therefore, they are both invaluable and extremely fragile.

\section{Conclusion}

If knowledge visualization is to function effectively, it has to include preliminary concepts. These are usually of a linguistic nature and embedded in a specific context. First, we have shown that people's possibilities of perception and thinking are shaped by language use. This is because language is a product of social acting and negotiating [9], it is culturally determined. After all, language is a constraint on using techniques of knowledge visualization. Second, it becomes apparent that learning has to be regarded as a constructing process which is influenced by the learner's cultural background.

These considerations lead to the problem of how to effectively use knowledge visualization which, at the same time, has to be impressive and has to work identically in all recipient's heads. But obviously knowledge visualization cannot transcend the cultural and linguistic constraints because it has to be conformable to existing linguistic patterns. Our excursus to a constructivist and linguistic concept of learning aimed to present a potential approach to resolve this issue. To use knowledge visualization effectively, the cultural context of communities and possible patterns of perception need to be studied intensely. Linguistic pat- terns and their acquisition for subsequent recall are important indicators for viable ways of visualization.

Some questions, especially concerning visualized metaphors, need much more attention and have yet to be resolved. Using knowledge visualization as an example, it appears that this discipline (momentarily) cannot be more than a mirror image of linguistic (or idiomatic) coinage, which in turn is a mirror image of culture and, again, context. Thus, this is a circular argument which can only be fundamentally solved theoretically. In this paper we presented first steps toward a semiology of the communication of knowledge.

\section{References}

[1] Helmuth Feilke. Sprachlicher Common sense und Kommunikation. Über den 'gesunden Menschenverstand', die Prägung der Kompetenz und die idiomatische Ordnung des Verstehens. In Der Deutschunterricht (VI). 1993. 6-21.

[2] Helmuth Feilke. Common sense-Kompetenz. Überlegungen zu einer Theorie des 'sympathischen' und 'natürlichen' Meinens und Verstehens. Frankfurt/Main, Suhrkamp. 1994.

[3] John Stewart, Ed. Beyond the symbol model: Reflections on the representational nature of language. Albany, NY, State University of New York Press. 1996.

[4] Dietrich Busse. Historische Semantik. Analyse eines Programms. Stuttgart, Klett-Cotta. 1987.

[5] Fritz Hermanns. Sprachgeschichte als Mentalitätsgeschichte. Überlegungen zu Sinn und Form und Gegenstand historischer Semantik. In Sprachgeschichte des Neuhochdeutschen. Gegenstände, Methoden, Theorien. Andreas Gardt, Klaus Mattheier and Oskar Reichmann, Eds. Tübingen, Niemeyer. 1995. 69-101.

[6] Joachim Scharloth. Die Semantik der Kulturen. Diskurssemantische Grundfiguren als Kategorien einer linguistischen Kulturanalyse. In Brisante Semantik. Neuere Konzepte und Forschungsergebnisse einer kulturwissenschaftlichen Linguistik. Dietrich Busse, Thomas Niehr and Martin Wengeler, Eds. Tübingen, Niemeyer. 2005. 119-135.

[7] Angelika Linke. Begriffsgeschichte - Diskursgeschichte - Sprachgebrauchsgeschichte. In Herausforderungen der Begriffsgeschichte. Carsten Dutt, Ed. Heidelberg, Winter. 2003. 39-49.

[8] George Lakoff and Mark Johnson. Metaphors we live by. Chicago, University of Chicago Press. 1980.

[9] Helmuth Feilke. Sprache als soziale Gestalt. Ausdruck, Prägung und die Ordnung der sprachlichen Typik. Frankfurt/Main, Suhrkamp. 1996.

[10] Martin J. Eppler and Remo A. Burkhard. Knowledge Visualization. In Encyclopedia of Knowledge Management. David G. Schwartz, Ed. Hershey, PA, Idea Group. 2005, forthcoming.

[11] Peter L. Berger and Thomas Luckmann. The social construction of reality: A treatise in the sociology of knowledge. Garden City, NY, Doubleday. 1966. 
[12] Klaus Merten. Wissensveränderung durch Medien. Aufriss und Kritik. In Wissensveränderung durch Medien. Theoretische Grundlagen und empirische Analysen. Karin Böhme-Dürr, Jürgen Emig and Norbert M. Seel, Eds. München, Saur. 1990. 21-39.

[13] Werner Wirth. Von der Information zum Wissen. Die Rolle der Rezeption für die Entstehung von Wissensunterschieden. Opladen, Westdeutscher Verlag. 1997.

[14] Martin J. Eppler and Remo A. Burkhard. Knowledge Visualization. Towards a New Discipline and its Fields of Application. ICA Working Paper 2/2004, University of Lugano. http://www.knowledgecommunication.org/ KnowledgeVisualizationWorkingPaper.pdf (Retrieved on February 21, 2005).

[15] Remo A. Burkhard and Michael Meier. Tube Map Visualization: Evaluation of a Novel Knowledge Visualization Application for the Transfer of Knowledge in Long-Term Projects. In Journal of Universal Computer Science (Special Issue on Business Process Oriented Knowledge Infrastructures). 2005, forthcoming.

[16] Michael Loebbert. Storymanagement: Der narrative Ansatz für Management und Beratung. Stuttgart, KlettCotta. 2003.

[17] Ikujiro Nonaka. The Knowledge-Creating Company. In Harvard Business Review 69 (6). 1991. 96-104.

[18] Remo A. Burkhard. Learning from Architects: The Difference between Knowledge Visualization and Information Visualization. In Eighth International Conference on Information Visualization (IV04). London. July 2004.

[19] Ludwig Wittgenstein. Philosophical Investigations. New York, Macmillan. 1958.

[20] Paul Watzlawick, Janet Beavin Bavelas and Don D. Jackson. Pragmatics of Human Communication: A Study of Interactional Patterns, Pathologies, and Paradoxes. New York, Norton. 1967.
[21] Lev S. Vygotsky. Thought and language. Cambridge, MA, MIT Press. 1986.

[22] Lev S. Vygotsky. Mind in society: The development of higher psychological processes. Cambridge, MA, Harvard University Press. 1978.

[23] Alex Kozulin. Vygotsky's psychology: A biography of ideas. New York, Harvester Wheatsheaf. 1990.

[24] Gerry Stahl. A Model of Collaborative KnowledgeBuilding. In Fourth International Conference of the Learning Sciences. Barry J. Fishman and Samuel F. O'Connor-Divelbiss, Eds. Mahwah, NJ, Erlbaum. 2000. 70-77.

[25] Remo A. Burkhard. Towards a Framework and a Model for Knowledge Visualization: Synergies between Information and Knowledge Visualization. In Knowledge and information visualization: Searching for synergies. Sigmar-Olaf Tergan and Tanja Keller, Eds. New York, Springer. 2005, forthcoming.

[26] Karl Mannheim. Ideology and Utopia: An Introduction to the Sociology of Knowledge. New York, Harcourt Brace Jovanovich. 1936.

[27] Peter F. Drucker. Post-Capitalist Society. New York, Harper. 1993.

[28] Gilbert Ryle. The concept of mind. London, Hutchinson's University Library. 1949.

[29] William Grey. Metaphor and Meaning. In Minerva: An Internet Journal of Philosophy (4). 2000. http://www.ul. ie/ philos/vol4/metaphor.html (Retrieved on February 22, 2005).

[30] Martin J. Eppler. The Image of Insight: The Use of Visual Metaphors in the Communication of Knowledge. In Journal of Universal Computer Science. Proceedings of I-KNOW '03. Graz. July 2003. 81-88. 